\title{
Experimental study on utilizing iron slag to stabilize $\mathrm{Cr}(\mathrm{VI})$-contaminated soils
}

\author{
O. A. B. Hassan \\ Department of Applied Physics and Electronics, \\ Umeå University, Sweden
}

\begin{abstract}
A laboratory study is conducted to test the capacity of two types of iron slag to stabilize Cr(VI)-contaminated soils. The slag samples are incorporated with soils in different proportions and the resulting leachate is tested using batch experiments. The feasibility of using iron is demonstrated as concentrations up to $1000 \mathrm{mg} \mathrm{Cr}(\mathrm{VI}) / \mathrm{kg}$ in the leachate of an alkaline soil are reduced to $0,7 \mathrm{mg}$ $\mathrm{Cr}(\mathrm{VI}) / \mathrm{kg}$ mix after 12 days, but to less than $5 \mathrm{mg} \mathrm{Cr}(\mathrm{VI}) / \mathrm{kg}$ mix after 7 days. Small particles size and L/S-ratio are, in most cases, favoured by the reducing agents to stabilize the contaminated soil. The study demonstrated that the iron slag can effectively stabilize $\mathrm{Cr}(\mathrm{VI})$-contaminated soils.
\end{abstract}

Keywords: environmental pollution, iron slag, Cr(VI), soil stabilization, reduction agents, leaching test, batch experiments.

\section{Introduction}

The pollution of soils caused by harmful heavy metals has led to new problems related to the sustainability of the ecosystem. In addition to its environmental effects, chemically-polluted soils can create technical problems associated with industry and the building sector, unless they are stabilized and remediated by one method or another. Chromium is one of the heavy metals that constitute one of the major causes of soil and water pollution.

In a broader sense, chromium has both beneficial and detrimental properties. The benefit of $\mathrm{Cr}$ is in its necessity for human nutrition (especially in glucose metabolism). The typical adult intake of $\mathrm{Cr}$ is less than $0.2 \mathrm{mg} / \mathrm{day}$ [1]. The detriment of $\mathrm{Cr}$ is in its toxicity. Most of the hexavalent chromium $\mathrm{Cr}$ (VI) compounds are toxic and are classified as carcinogenic and mutagenic to both 
humans and animals and can cause lung cancer, ulceration of skin, eyes and mucus membranes [2].

Technically, $\mathrm{Cr}(\mathrm{VI})$ is widely used in industrial applications such as metal plating, tannery works, anticorrosive agents, rust proofing and manufacturing of dyes and inks. The wide spread presence of chromium in the environment is due mainly to burning of fossil fuels. The major sources of $\mathrm{Cr}$-containing wastewater are factories producing industrial inorganic chemicals and pigments, $\mathrm{Cr}$ plating and polishing operations, wood-preserving facilities, and petroleum refineries. It is the anthropogenic deposition of these compounds in form of chromate ( $\left.\mathrm{CrO}^{--}\right)$ and dichromate $\left(\mathrm{CrO}^{--}\right)$that causes environmental pollution of soil and groundwater.

In contrast, $\mathrm{Cr}(\mathrm{III})$ species are generally regarded as benign i.e., less toxic and less mobile. Redox, precipitation and sorption processes are the main factors that affect the chromium species in the soil. Consequently, a possible strategy to remediate the $\mathrm{Cr}(\mathrm{VI})$-contaminated soils is to reduce $\mathrm{Cr}(\mathrm{VI})$ to $\mathrm{Cr}(\mathrm{III})$. The in situ stabilization of soil contaminated $\mathrm{Cr}(\mathrm{VI})$ is necessary to inhibit any possible migration of chromium plume from soil to the groundwater. The remediation by reduction, however, is not free from disadvantages. In order to mitigate the polluted soils with $\mathrm{Cr}(\mathrm{VI})$, remediation plans have to be both economical with low side effects. Reduction agents for $\mathrm{Cr}(\mathrm{VI})$ can be ferrous sulphate, bisulphate, and sulphides. Potential drawbacks of these agents for soil and landfill remediation include the necessity for $\mathrm{pH}$ adjustment prior to mixing with the reducing agent such as $\mathrm{Fe}(0)$. This, however, depends on the chemical and physical properties of the soil and the concentrations of $\mathrm{Cr}(\mathrm{VI})$ in the soil.

Several stabilizing agents are used for treatment of $\mathrm{Cr}(\mathrm{VI})$ contaminated soils and among them is Portland cement. However, it has been shown that through leaching tests that $\mathrm{Cr}(\mathrm{VI})$ is not permanently immobilized by addition of Portland cement [3]. Consequently, there is, often, two stages that should be carried out for stabilization of chromium in soil, first is to reduce $\mathrm{Cr}(\mathrm{VI})$ to $\mathrm{Cr}(\mathrm{III})$ and second is to stabilize $\mathrm{Cr}(\mathrm{III})$ by precipitating of chromium hydroxides.

For the case of using iron slag in the stabilization of soils contaminated with $\mathrm{Cr}(\mathrm{VI})$, the reduction of $\mathrm{Cr}(\mathrm{VI})$ to $\mathrm{Cr}(\mathrm{III})$ and subsequent stabilization have been observed for cements containing ground granulated blast furnace slag (see e.g., [4-8]). The reason is the low redox potential of sulphur-bearing slag modified cements. The iron slag generally contains sulphur and $\mathrm{FeS}$ depending on the method of manufacturing steel as it is a by-product. The use of blast furnace slag-modified grouts for in situ stabilization of chromium-contaminated soil was evaluated [8]. Concentrations up to $1000 \mathrm{ppm}$ in spiked soils were stabilized with slag-modified grouts to give TCLP leachate concentrations less than 5.0 $\mathrm{ppm}$. The slag-modified grouts were found effective over a range of mix proportions. The percentage of slag/cement used is $80 \% / 20 \%$ grout and it was found that the addition of slag causes partial reduction of $\mathrm{Cr}(\mathrm{VI})$ to $\mathrm{Cr}(\mathrm{III})$ and thereby it is possible to bypass a pre-treatment stage to reduce $\mathrm{Cr}(\mathrm{VI})$.

In conclusion, the iron slag can be a potential reducing agent for the treatment of soils contaminated with $\mathrm{Cr}(\mathrm{VI})$. This paper attempts to test the capacity of two 
types of iron slag to stabilize Cr(VI)-contaminated soils. Moreover, the slag alone, as a reductant, without additions is tested to check its capacity to treat $\mathrm{Cr}(\mathrm{VI})$-contaminated soils. In this paper, local slag brought from a mineral company in Denmark is used and tested for this purpose

\section{Experimental methods}

\subsection{Materials}

\subsubsection{Contaminated soil}

For the laboratory study, soil sample were taken from a $\mathrm{Cr}(\mathrm{VI})$-polluted site located in Roskilde (Denmark). The soil is an anthropogenic and alkaline material composed of chromate ore processing residue, mixed with lime. The source factory is a tannery whereby chromium is used in the manufacturing processes.

\subsubsection{Iron slag}

Slag is a by-product material from steelmaking industry. Disposal of this slag bears economical costs in addition to the responsibility of ensuring disposal in landfill sites in accordance with environmental regulations. From a chemical point of view, the slag is a complex combination of chemicals, metal oxides such as sulfur, calcium and iron. In the past and currently, slag has been used as an aggregate in road construction works along with its application in construction materials such as cement slag (ground slag with clinker). Other applications are the production of mineral wool or using it as cement substitutes in masonry mortars.

For the experimental study, two kinds of slag have been tested: furnace slag (yellow-coloured material with a weight density similar to the soil, particle size: 1-7 $\mathrm{mm}$ ) and blast furnace slag (black-coloured and has high weight density, particle size: 1-3 $\mathrm{mm}$ ), as shown in fig. 1 .

\subsubsection{Furnace slag (FS)}

Furnace slag is a mixture of impure steel byproducts. It is a by-product that originates from processing the crude substances in steel in an electro-furnace in order to catch the impurities in the steel. During the moulding process the impurities are separated and collected. The amount of slag is dependent on the purity of steel byproduct and the amount of the moulded steel. The final disposal of this slag is at the company site; FS is usually used as a filling material in the road constructions and in asphalt production.

\subsubsection{Blast furnace slag (BFS)}

In the first stage of moulding steel, impurities in form of iron byproducts (e.g., furnace slag) will be removed. The second stage of steel manufacturing is to clean up the steel and free it once again from the iron impurities. The byproducts in the second stage are denoted blast-furnace slag (BFS); particle size is 1-3 mm. The main usage of this slag is to use it as a membrane for different applications such as for dams, etc; BFS can also be used in the manufacturing of some construction materials. 


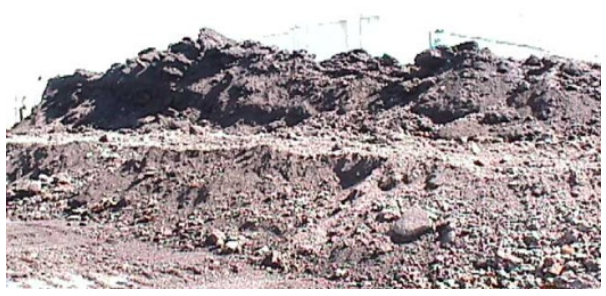

A

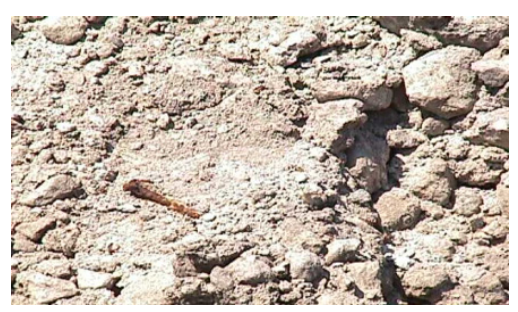

B

Figure 1: $\quad$ (A) Furnace slag; (B) a close-eye picture of blast furnace slag after drying and crushing.

\subsection{Extraction method and batch experiments}

The amount of $\mathrm{Cr}, \mathrm{Mn}$ and $\mathrm{Fe}$ in the soil is determined by using acid extraction method. Soil samples of $1 \mathrm{gm}$ are digested by $20 \mathrm{ml}$ half-concentrated ( $7 \mathrm{~N}$ HNO3) and put in oven in temperature $125{ }^{\circ} \mathrm{C}$ for $30 \mathrm{~min}$. After cooling off and decanting, the extract is made up to $100 \mathrm{ml}$. The batch experiments are conducted by adding an amount of slag corresponding to a specific percentage of total solids together with soil. Then, the total solids are mixed with deionized ID water corresponding to the liquid/ solid (L/S) ratio. The samples are weighted and mixed homogeneously in a $50 \mathrm{ml}$ beaker mixed with a deionized ID water according to $\mathrm{L} / \mathrm{S}$ ratio. Two replicates for each $\mathrm{L} / \mathrm{S}$ - and mix ratios are used. The samples are then measured for $\mathrm{pH}$ at time $=0$ and put in a shaker for 190 $\mathrm{puk} / \mathrm{min}$, which is little above middle velocity for an efficient rate of mixing. At different times, the leachate from the batches for $\mathrm{Cr}$ analysis is taken and centrifuged for around $12 \mathrm{~min}$ to isolate the precipitants (usually $\mathrm{Cr}$ (III)) from the liquid phase (usually $\mathrm{Cr}(\mathrm{VI})$ ). The supernatant is then transferred immediately to glass samples and acidified to $\mathrm{pH}<1$ and put in fridge in the lab for a later analysis of total dissolved chromium. The concentration of total $\mathrm{Cr}$ is determined by flame-emission atomic absorption spectroscopy. The solution's $\mathrm{pH}$ in the batch experiments is measured using $\mathrm{pH}$ colour strips readable to 0.3 $\mathrm{pH}$ unit precision. The $\mathrm{pH}$ is determined using a combination of $\mathrm{pH}$ electrode, calibrated using $\mathrm{pH} 4, \mathrm{pH} 7$ and $\mathrm{pH} 9$ standard buffers.

\subsection{Mix proportions of soil samples with slag and water}

The mix proportions of batches used for analysis are shown in Table 1. As can be noted here, two mixes of soil: BFS/FS ratios are chosen, 1:1 and 1:4 but with different $\mathrm{L} / \mathrm{S}$ ratios.

\section{Results and discussion}

In the following, practical parameters with respect to remediation plan for reducing $\mathrm{Cr}$ (VI) to $\mathrm{Cr}$ (III) are investigated. 
Table 1: $\quad$ Mix proportions of soil samples with BFS or FS.

\begin{tabular}{|r|r|l|l|l|l|}
\hline Batch & $\begin{array}{l}\text { Soil, } \\
\text { gm } \\
\text { gm }\end{array}$ & ID & & & \\
ml water, & L/S ratio & $\begin{array}{l}\text { Soil: } \\
\text { BFS/FS } \\
\text { ratio }\end{array}$ \\
\hline $\mathrm{A}$ & 5 & 5 & 20 & $2: 1$ & $1: 1$ \\
\hline $\mathrm{B}$ & 2 & 8 & 20 & $2: 1$ & $1: 4$ \\
\hline $\mathrm{C}$ & 2,5 & 2,5 & 25 & $5: 1$ & $1: 1$ \\
\hline $\mathrm{D}$ & 1 & 4 & 25 & $5: 1$ & $1: 4$ \\
\hline $\mathrm{E}$ & 2,5 & 2,5 & 40 & $8: 1$ & $1: 1$ \\
\hline $\mathrm{F}$ & 1 & 4 & 40 & $8: 1$ & $1: 4$ \\
\hline $\mathrm{G}$ & 2,5 & 2,5 & 50 & $10: 1$ & $1: 1$ \\
\hline $\mathrm{H}$ & 1 & 4 & 50 & $10: 1$ & $1: 4$ \\
\hline
\end{tabular}

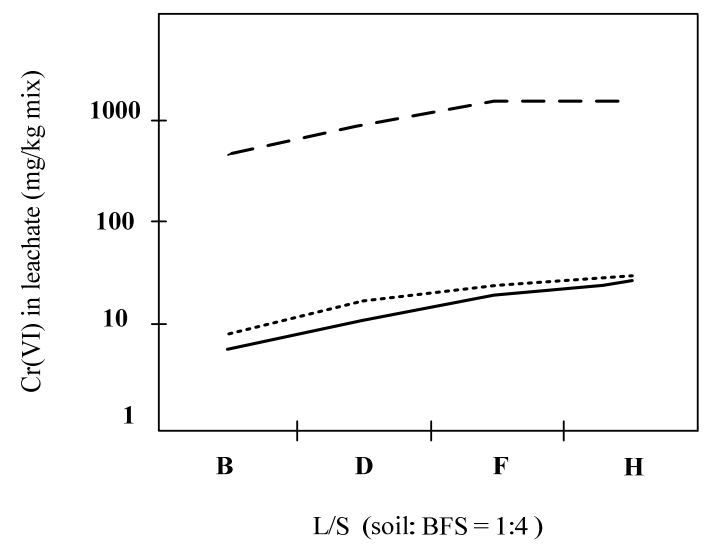

Figure 2: $\quad \mathrm{L} / \mathrm{S}$, mix ratio of batches with BFS (soil: $\mathrm{BFS}=1: 4$ ) vs. $\mathrm{Cr}(\mathrm{VI})$ concentrations in leachate, ------, control samples; ......, after 4 days; - after 7 days; see table 1 for notations.

\subsection{Blast furnace slag (BFS)}

\subsubsection{Effects of L/S-ratio and time}

Fig. 2 and fig. 3 show the mix- and L/S ratio effect on the removal of chromium from the leachate after mixing BFS with soil; the results concern the case in which soil: BFS ratios is 1:4 (batch codes: $\mathrm{B}, \mathrm{D}, \mathrm{F}, \mathrm{H}$ ) and 1:1 (batch codes: A, $\mathrm{C}, \mathrm{E}, \mathrm{G})$, respectively. For the soil mix ratio $1: 4$, the optimum $\mathrm{L} / \mathrm{S}$ ratio is $2: 1$; after 7 days from mixing, 98.7\% $\mathrm{Cr}(\mathrm{VI})$ was reduced by BFS. For the soil mix ratio $1: 1$, the removal of chromium is $70 \%$ less than for the mix ratio $1: 4$ for $\mathrm{L} / \mathrm{S}$ $=2: 1$. Once again, the optimum liquid-to-solid ratio is $L / S=2: 1$. 


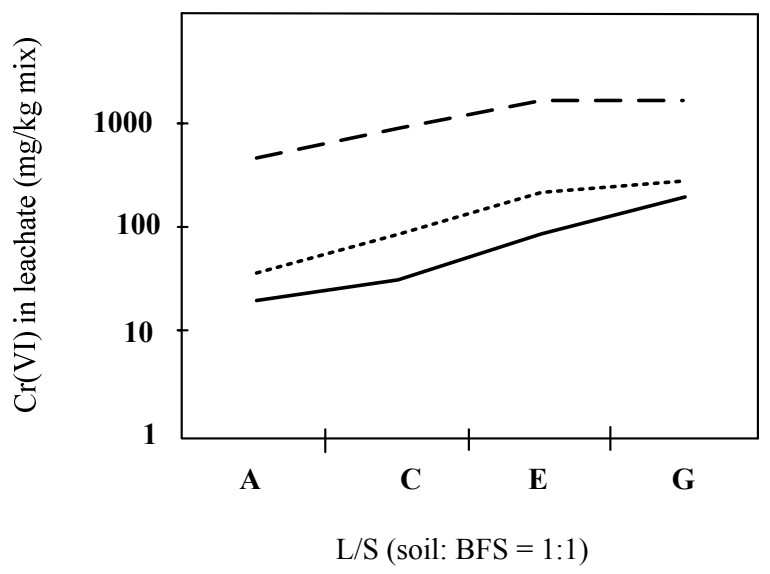

Figure 3: $\quad \mathrm{L} / \mathrm{S}$, mix ratio of batches with $\mathrm{BFS}$ (soil: $\mathrm{BFS}=1: 1) v s . \mathrm{Cr}(\mathrm{VI})$ concentrations in leachate, ------, control samples; ......., after 4 days; — after 7 days; see table 1 for notations.

Consequently, the BFS has a good capacity for the removal of $\mathrm{Cr}(\mathrm{VI})$ from the leachate as compared with the control soil samples, which contains only chromium (without a reductant). The results indicate that as the percentage of the slag incorporated increase, the removal of $\mathrm{Cr}(\mathrm{VI})$ also increases. However, higher $\mathrm{L} / \mathrm{S}$ values are not favoured for the stabilization process. Additionally, the time of reaction has an influence and that after a definite time; most of the $\mathrm{Cr}(\mathrm{VI})$ is reduced. A timeframe in which reaction stabilizes and most of $\mathrm{Cr}(\mathrm{VI})$ is reduced can be set to 7 days.

\subsubsection{Reaction effect on $\mathrm{pH}$}

The reaction effect is shown in fig. 4. As can be seen, the reaction between the slag and $\mathrm{Cr}(\mathrm{VI})$ in soil particles increases the hydrogen ion concentrations. In this manner, the reaction is alkalinity generating and acidity consuming. Within time, $\mathrm{pH}$ increases. Obviously, the BFS adds hydroxides to the leachate through the hydration of metals oxides contained in the slag.

\subsubsection{The effect of $\mathrm{pH}$ modification}

The effect of $\mathrm{pH}$ modification on the reduction process is carried out by adjusting the $\mathrm{pH}$ to 5 for 24 hours by using $\mathrm{pH}$ static. The results demonstrated that the acidification reduces the efficiency of BFS as a reductant. It is thought that the process of continuous addition of acid will desorb the $\mathrm{Cr}(\mathrm{VI})$ particles and lead to migration of $\mathrm{Cr}(\mathrm{VI})$ thereby increasing its concentrations in the leachate.

\subsubsection{Effect of particle size}

The results are shown in fig. 5 and fig. 6 . As expected, the mix proportion soil: $\mathrm{BFS}=1: 4$ (batch B) is more effective than the mix ratio 1:1 (batch A). The results suggest that smaller particle sizes are favoured by the reduction and the 


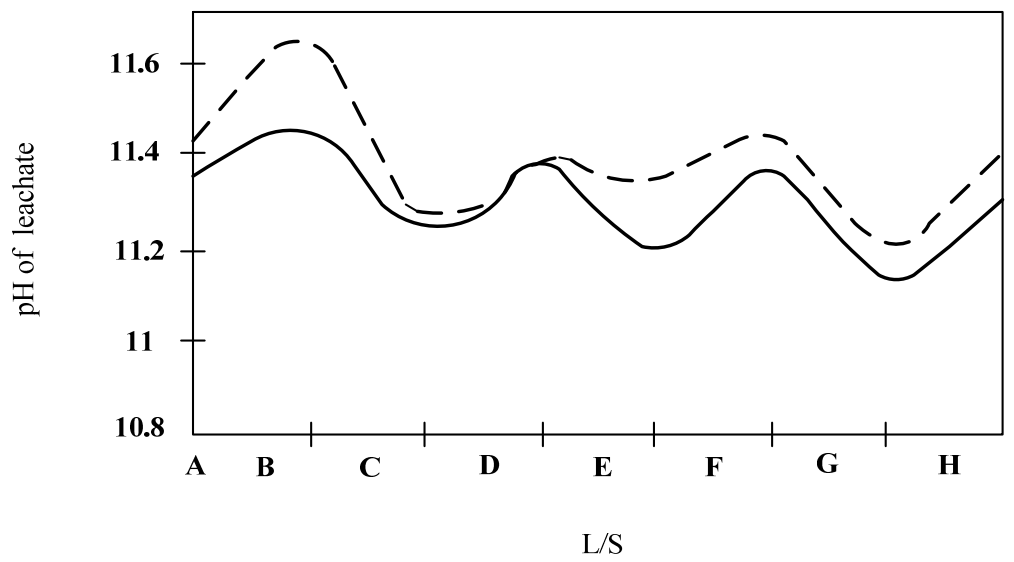

Figure 4: L/S for different mix ratios of batches with BFS vs. $\mathrm{pH}$ of the leachate, -------, after 7 days; - after 4 days; see table 1 for notations.

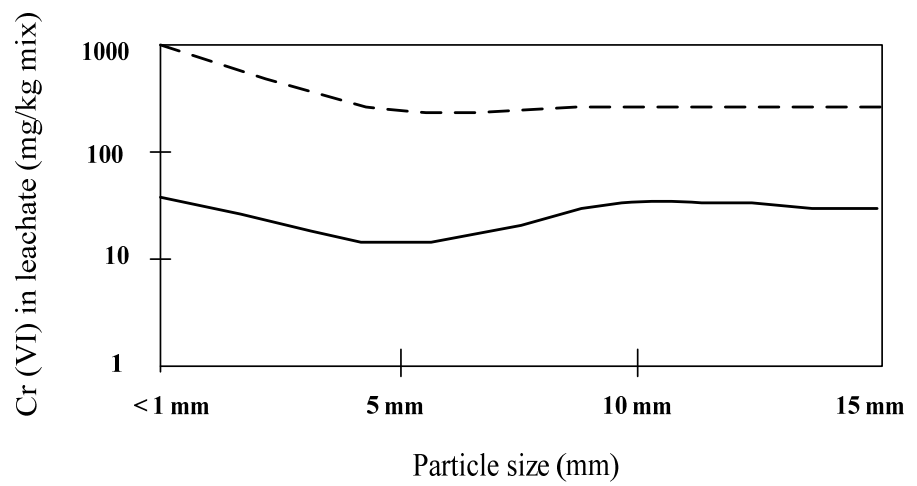

Figure 5: Effect of soil particle size on the reduction of $\mathrm{Cr}(\mathrm{VI})$ by $\mathrm{BFS}$ for batch A (soil: BFS mix proportionality is 1:1). Time of measurement is after 3 days and $\mathrm{L} / \mathrm{S}=2: 1$. -------, control $(100 \%$ soil); — batch A; see table 1 for notations.

efficiency of stabilization increases as particle sizes decreases. It noteworthy to indicate here that smaller particle size in general is the significant contributor to the obtained results.

\subsection{Furnace slag (FS)}

\subsubsection{Effects of L/S-ratio and time}

Fig. 7 shows L/S -ratio effect on the removal of chromium from the leachate after mixing FS with mix ratio 1:4 (soil: FS), batch B. As can be seen, the 


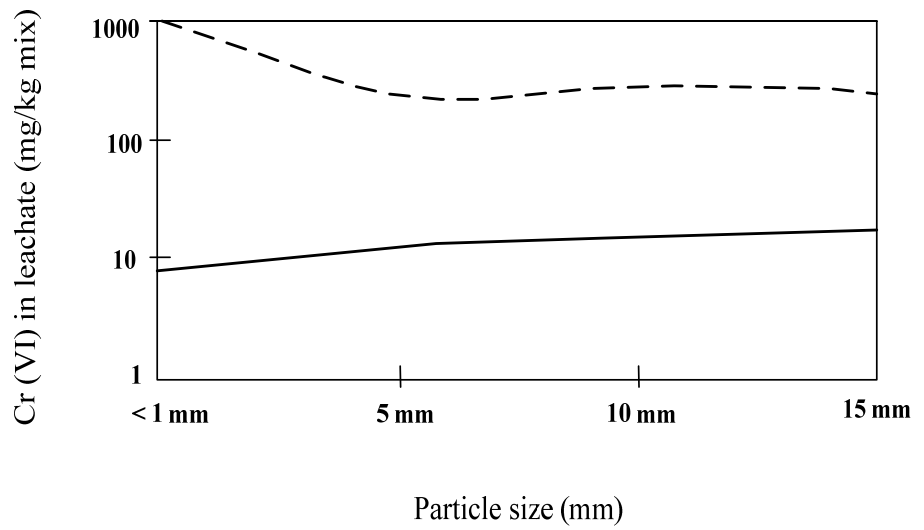

Figure 6: Effect of soil particle size on the reduction of $\mathrm{Cr}(\mathrm{VI})$ by BFS for batch B (soil: BFS mix proportionality is 1:4). Time of measurement is after 3 days and $\mathrm{L} / \mathrm{S}=2: 1$. ------ control $(100 \%$ soil); —— batch B; see table 1 for notations.

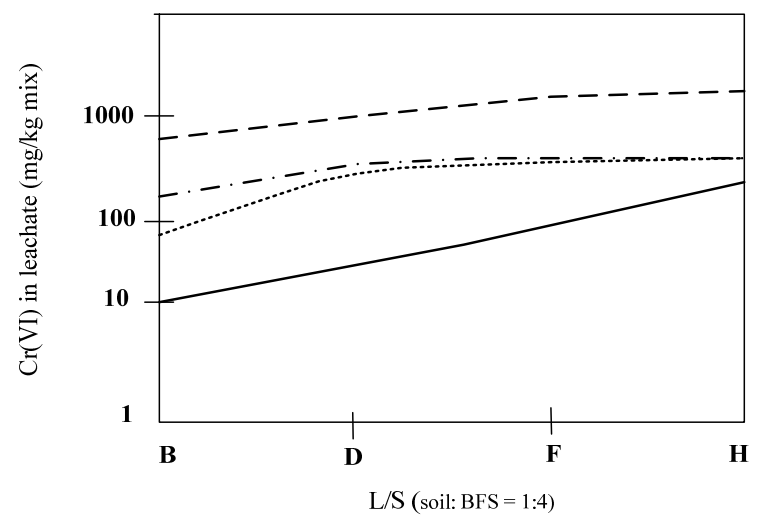

Figure 7: L/S, mix ratio of batches with FS (soil: $\mathrm{FS}=1: 4)$ vs. $\mathrm{Cr}(\mathrm{VI})$ concentrations in leachate, ------, control samples; --.---, after 3 days; ......., after 7 days; - after 16 days; see table 1 for notations.

removal of chromium from the leachate is continuous with time and that the same conclusions for the case of BFS can be drawn here too. Additionally, it may be hypothesized that a slow process of mass transfer of metal ions from the solid FS to the water occurs and the diffusive transport of these metal ions is slower than the case with BFS. The decrease of $\mathrm{Cr}(\mathrm{VI})$ concentrations by FS is not dependant on concentrations of $\mathrm{Cr}(\mathrm{VI})$ released from soil matrix because it is fluctuating while the removal by FS is increasing with time. As the case with 
$\mathrm{BFS}$, the ratio $\mathrm{L} / \mathrm{S}=2$ is found to yield the best stabilization results. There is a potential that after a longer reaction period ( $>16$ days), almost all the chromium will be removed from the leachate.

\subsubsection{Reaction effect on $\mathrm{pH}$}

Fig. 8 shows the effect of mixing FS and soil on the hydrogen ions concentration for different times. As can be seen, the $\mathrm{pH}$ is increasing within time. This indicates that a continuous reaction between FS and the $\mathrm{Cr}(\mathrm{VI})$ released from soil matrix. The increase of $\mathrm{pH}$ indicates that $\mathrm{FS}$ is acidity consuming and alkalinity generating. In this manner, FS has similar effect as BFS.

\subsubsection{Effect of $\mathrm{pH}$ modification}

The same effect as that for the BFS was found as well with respect to FS.

\subsection{Effect of mixing FS and BFS}

The previous figures show clearly that FS is less effective in removing $\mathrm{Cr}$ (VI) than BFS. For instance, referring to fig. 7, 85\% of the chromium is stabilized for $\mathrm{L} / \mathrm{S}=2: 1$ after 7 days; by comparison, referring to fig. $2,98.7 \%$ of chromium is stabilized after 7 days. It may be hypothesized that mechanism by which the slag removes $\mathrm{Cr}(\mathrm{VI})$ is by adsorption for FS and by a coupled effect of adsorption and reduction for BFS. Fig. 9 shows the reduction improvement capacity of mixing BFS and FS. As can be seen, a reduction up to $96,4 \%$ occurred after 7 days for $\mathrm{L} / \mathrm{S}=2: 1$. This may be compared with $85 \%$ reduction with the same condition by the FS alone and $98,7 \%$ by the BFS alone after 7 days, as mentioned above. Consequently, mixing the BFS together with FS can result in improving the capacity of FS to remove chromium from the leachate. Further, the liquid to soil ratio $\mathrm{L} / \mathrm{S}=2: 1$ was found as the best $\mathrm{L} / \mathrm{S}$ among the samples studied, which resulted in lowest chromium detected in the leachate.

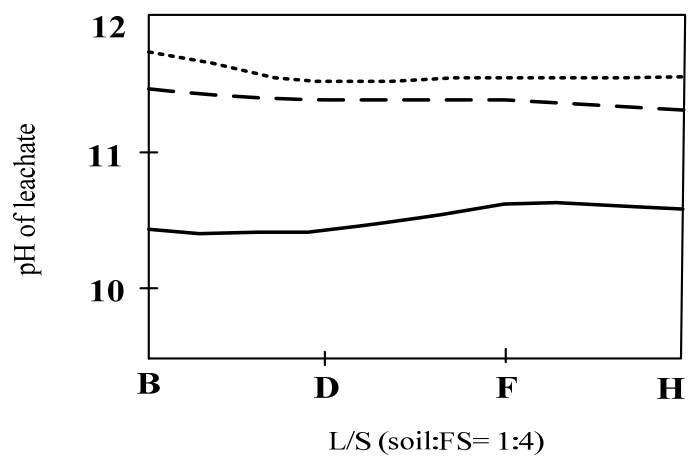

Figure 8: $\quad \mathrm{L} / \mathrm{S}$, mix ratio for $\mathrm{FS}$ (soil: $\mathrm{FS}=1: 4$ ) vs. $\mathrm{pH}$ of the leachate. start; -------, after 3 days ........, after 7 days; see table 1 for notations. 


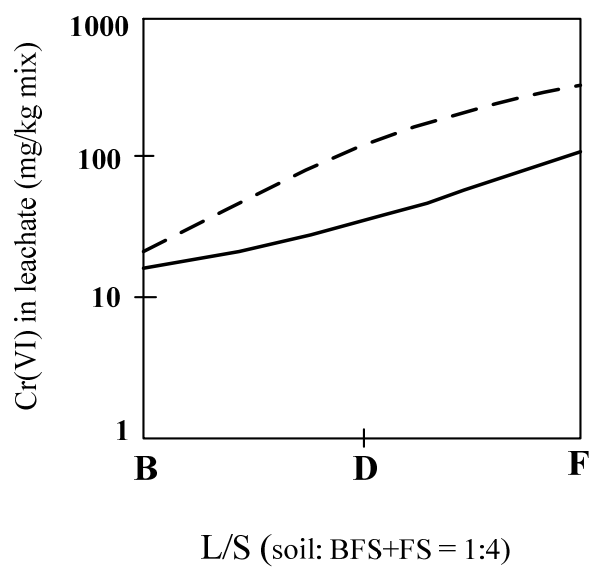

Figure 9: $\quad \mathrm{L} / \mathrm{S}$, mix ratio of batches with $\mathrm{BFS}+\mathrm{FS}$ (soil: $\mathrm{BFS}+\mathrm{FS}=1: 4) v s$. $\mathrm{Cr}(\mathrm{VI})$ concentrations in leachate, - - - - - -, after 4 days; - — after 7 days. The slag mix ratio of the batches B, D, E is BFS: FS 1:1.

\section{Concluding remarks}

$\mathrm{Cr}(\mathrm{IV})$ leaching constitutes a very challenging research area where a number of soil geochemical and mineralogical attributes play a significant role. Alkaline soils contaminated with hexavalent chromium $\mathrm{Cr}(\mathrm{VI})$ can effectively be stabilized with blast furnace slag BFS and furnace slag FS. The reduction capacity of the slag is attributed to its content of $\mathrm{FeO}, \mathrm{FeS}$, and $\mathrm{SO} 2$ contained in the slag in addition to its lower redox potential Eh. It has been amply demonstrated that $\mathrm{Cr}(\mathrm{VI})$ leaching is not only a function of reduction of $\mathrm{Cr}(\mathrm{VI})$. More specifically, a significant portion of the immobilized $\mathrm{Cr}(\mathrm{VI})$ at a high $\mathrm{pH}$ is bound to calcium aluminium chromate hydrate crystalline compounds. The presence of sulphate (usually present in iron slag) has also been shown to play a very important role in $\mathrm{Cr}(\mathrm{VI})$ immobilization by the formation of calcium aluminium sulphate chromate insoluble crystalline compounds.

The effect of particles size, L/S-ratio, time and $\mathrm{pH}$ was studied on the reduction of $\mathrm{Cr}(\mathrm{VI})$ in the soils and found that in most cases $\mathrm{L} / \mathrm{S}=2: 1$ and particles size of soil $<1 \mathrm{~mm}$ resulted in lowest $\mathrm{Cr}(\mathrm{VI})$ concentration, after reduction occurrence among the samples studied.

The results suggest that FS is less effective in removing $\mathrm{Cr}(\mathrm{VI})$ than BFS. However, mixing FS and BFS together in equal ratio and then mix them with soil and ID water improved the capacity of FS for treating $\mathrm{Cr}(\mathrm{VI})$-contaminated soils.

Finally, from the economical point of view, the iron slag is very cheap material as compared with other reductions agents of chromium-contaminated soils (e.g., zero-valent iron). Consequently, the treatment of soils contaminated with chromium by iron slag is both cost-effective and practical. 


\section{References}

[1] Alloway, B.J. (editor), Heavy Metals in soils.2nd edition, Chapman and Hall, Glasgow, 1995.

[2] Katz, S.A; Salem H., The biological and Environmental chemistry of chromium; VCH: New York, 1994.

[3] Zamorani et al, Chemical properties measurements and leaching behavior of chromium compounds solidified in a cement matrix. Waste management 8:239-245, 1988.

[4] Dermatas, D. and Meng X. Utilization of Fly Ash for stabilization /solidification of heavy metal contaminated soils, journal of engineering geology, Elsevier Science, Vol. 70/3-4, pp 377-394, 2003.

[5] Hassan, O. A. B, Stabilization of coils contaminated with $\mathrm{Cr}(\mathrm{VI})$-new methods, M.Sc thesis, Department of Environmental Science and Engineering, Technical University of Denmark, 1999.

[6] Kindness et al, Immobilization of chromium in cement matrices. Waste management, 14:3-11, 1994.

[7] Mollah, M.Y et al, The interfacial chemistry of solidification/stabilization of metals in cement and pozzolanic material systems, Waste management, vol.15, No.2, pp 137-148, 1995.

[8] Allan, M.L.; Kukacka L.E, Blast furnace slag-modified grouts for in situ stabilization of chromium-contaminated soil, Waste management, Vol. 15, No.3, pp.193 202,1995. 